\title{
Effect of study group on grade 9 students' achievement in solving trigonometric problems
}

Gurat, Melanie $\measuredangle$

Saint Mary’s University, Philippines (melanie.gurat@yahoo.com)

Sagun, Mary Joy

Saint Mary’s University, Philippines (maryjoysagun25@yahoo.com)

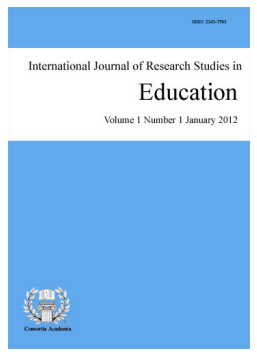

ISSN: 2243-7703 Online ISSN: 2243-7711

Received: 6 July 2017

\section{Abstract}

Trigonometry serves as an important precursor to calculus as well as college level courses. However, a possible factor that affects students from learning is teachers' strategies in teaching. Several studies reveal that cooperative learning such as study group can increase achievement of students in mathematics. This study focused on the effects of study groups on the grade 9 students' achievement in trigonometric problems. It sought to identify the achievement of the students in problem solving before and after the interventions and to compare the interventions, the group taught with study groups and taught with the existing method. The study used true experimental design particularly pretest-posttest control group design. The study was analyzed through frequency count and percentage of scores, Wilcoxon rank test, and t-test for independents samples. The subjects of the study were the Grade 9 students in a public high school in Nueva Vizcaya, Philippines. The results revealed that majority of the students' achievements increased. Moreover, the intervention with a study group and the existing method can improve the students' performance in solving trigonometric problems. Furthermore, the result suggests that study group method was more effective than the existing method.

Keywords: cooperative learning; existing method; problem solving; mathematics education; students' performance 


\section{Effect of study group on grade 9 students' achievement in solving trigonometric problems}

\section{Introduction}

Problem solving is one of major aspect in mathematics curriculum which students are required to apply and to incorporate many concepts in mathematics and skills as well as making a decision (Tambychik \& Meerah, 2010). It has an important role in the mathematics education (National Council of Teachers of Mathematics, 2016). It was emphasized in the National Council of Teachers of Mathematics that all students in all grades should enable to "build new mathematical knowledge through problem solving, solve problems that arise in mathematics and in other contexts, apply and adapt a variety of appropriate strategies to solve problems, and monitor and reflect on the process of mathematical problem solving" (NCTM 2000, p. 52; as cited by Williams, 2003). In mathematics problem solving, students are expected to formulate and solve problems to represent unfamiliar or meaningful situations; plan their approaches; or apply their existing strategies to seek solutions (Kargas \& Stephen, 2014). It improves the skills of the students and their ability to think reasonably, artistically and carefully (Siniguian, 2007).

One particular area in mathematics that is applied in problem solving is trigonometry. Trigonometry is important because it gives students good practice in employing the algebraic skills and most importantly, it benefits students' thinking processes. Hence, the process of making a connection in trigonometry will be useful in subsequent math classes (Vajiac \& Snow, 2009). It is an important subject in the high school mathematics curriculum. It is one of the secondary mathematics topics that are taught early and that link algebraic, geometric, and graphical reasoning; trigonometry can serve as an important precursor to calculus as well as college level courses (Weber, Knott, \& Evitts, 2008). However, mathematics is like a not existing language which students cannot acquaint on it. In a mathematics classroom, some students talked only $20 \%$ at a time and some are not talking at all (Kotsopoulos, 2007). Moreover, students were reported to have difficulties in mathematics problem solving. When students do not succeed in problem solving they may feel bad and cause them to avoid math in the future (Tambychick \& Meerah, 2010). Since students cannot get the topic, they do not have any time as the teacher moves on the next topic (Gallup, 2005). One factor that could affect the students in learning is the instruction used to them. Trigonometry instruction emphasizes procedural, paper-and-pencil skills at the expense of deep understanding (Hirsch, Weinhold, \& Nichols, 1991, as cited by Weber, Knott, \& Evitts, 2008).

Effort has been made by other researchers to find for effective strategies in teaching. Choi-Koh (2003) used a graphing calculator in teaching trigonometry and found that the effect was to advance the thinking process of the students. Weber, Knott, and Evitts (2008) used geometric approach to trigonometry and found that this can lead students to understand trigonometric operations as functions while traditional instruction does not. Bressoud (2010) presented the historical reflection on teaching geometry suggesting it to use history in teaching to show to the students that mathematics comes from real people who struggled with the same concepts. Franz and Pope (2005) suggested the use of children's stories to deepen the students' understanding of mathematics.

On the other hand, meetings and casual discussions are ways to air ideas and thoughts to solve problems (Hadler, 2015). It is collaborative and communal, not competitive and isolated (Wiersema, 2000). Many instructors used group work to improve the learning of the students (Brame \& Biel, 2015). Using collaborative activities in teaching is better than the traditional method (Tilan, 2003). Cooperative learning as defined by Johnson and Johnson (2000, cited by Walmsley \& Muniz, 2003) is a "relationship in a group of students that requires positive interdependence (a sense of sink or swim together), individual accountability (each of us has to contribute and learn), interpersonal skills (communication, trust, leadership, decision making and conflict resolution), face-to-face promotive interaction, and processing (reflecting how well the team is functioning and how to function even better)." It can also develop students' skill in communicating mathematics. It can also 
increase academic achievement, and successful social academic group interactions (Walmsley \& Muniz, 2003). Hence, cooperative learning can be used to foster active student learning, which is an important dimension of mathematical learning and is highly endorsed by mathematics educators and researchers (Tarim, 2009).

Furthermore, students are obligated to participate in a study group. When students gather, they brainstorm ideas and problems that would be too difficult to solve for an individual alone. Several studies reveal the effect of the study group or cooperative learning. Charry (2005) found that small groups solved problems better than those individuals who worked alone. Lau (2006) found that peer group study approach was in valuable in teaching mathematical concepts and acquiring problem-solving skills. Similarly, Vaughan (2002) also found positive gain in achievement in mathematics. Tarim and Akdeniz (2007) who used two cooperative learning Team Assisted Individualization (TAI) and Student Teams-Achievement Divisions (STAD found that both methods have a positive effect on students' mathematics achievements. However, the TAI method had a more significant effect than the STAD. Both methods can improve attitudes of students in mathematics. Also, Dotson (2001) compared the achievement scores of the students who participated and who did not participate in the cooperative learning and obtained the same result that cooperative learning can be used successfully even for diverse learners. In particular, Nebesniak (2007) found that cooperative skills are more effective if applied in concrete situations as compared to problems that require more abstract thinking. Kalaian and Kasim (2014) used the same method in statistics and revealed that collaborative learning method supported the effectiveness of the small-group learning methods in improving the academic achievement of the students. However, Ding, Li, Piccolo, and Kulm (2007) found that length, choice and frequency of teachers' intervention frequency may influence the quality of the intervention. In addition to that, they also suggested that students' mathematical thinking and understanding should also be addressed regardless of the interventions used by the teachers.

Moreover, study group was also applied in Physics subject such as the study conducted by Hussain, Anwar and Majoka (2011) determined the effect of peer group activity on the academic achievement of the students in physics and found that the group taught with peer group method performed better than the group taught in traditional method in the area of knowledge, comprehension, and application. Similarly, Adolphus, Alamina, and Aderonmu (2013) also examined the effects of collaborative learning in the problem and yielded the same result. In economic instruction, Yamarik (2007) also obtained higher achievement after using cooperative learning. In language learning, Baghdadi and Keskes (2014) also supported that small group activity contributed to the development of students' performance in grammar.

Aside from the improvement in achievement, cooperative learning has positive gain in attitudes of the students (Vaughan, 2002). This was supported by Tarim and Akdeniz (2007) who used two cooperative learning Team Assisted Individualization (TAI) and Student Teams-Achievement Divisions (STAD). They found no significant difference between the attitudes using TAI and STAD. Both methods can improve attitudes of students in mathematics. Moreover, if collaborative learning was used properly, it can also help learners meet the social interaction, specific learning, and objectives in structured groups. It also promotes social interaction in facilitating knowledge construction (Makewa, Gitonga, Ngussa, Njoroge, \& Kuboja, 2014). Another effect of cooperative learning was also determined such as teachers and students were motivated and enjoyed by the differentiated instruction (Tieso, 2002), students became more motivated, not competitive, more aware on the process of problem solving, and there is improved in the English language skills (Morgan, 2005) and collaborative learning increases the confidence level of the students and involvement in learning process in mathematics (Nebesniak, 2007). In addition, effective use of cooperative learning in the classroom can positively affect students' social skills, self-esteem, and intergroup relationships (Walmsley \& Muniz, 2003). However, one disadvantage of the study group is equality in the distribution of tasks. Expert in the group tended to dominate interactions during group activities (Esmonde, 2009). Aside from that, studies of Cronin and McCabe (2017) showed negative result of by group activity. They found that students who worked alone had significantly improved laboratory technique in biology class compared to student working in a group.

Saint Mary's University, a Catholic institution in the Philippines also used Student Study Group Program or 
SSGP from the different departments such as School of Engineering and Architecture, School of Accountancy and School of Education to enhance the learning of the students. However, the program was only used in college level and not in high school. With the aforementioned discussion, this study aimed to know the effect of study groups on Grade 9 students' achievement in problem solving particularly in Trigonometry in which the Grade 9 students are exposed.

\subsection{Statement of the Objective}

The study aimed to know the effect of study groups on Grade 9 students' achievement in problem solving particularly in Trigonometry. Specifically, this study aimed to describe the achievement of the students in problem solving. This study also sought to find the significant difference between the achievement of the students in problem solving before and after the intervention with the study group and the existing method. The significant difference between the achievements of the students when they are taught with study groups and the existing method was also determined.

\subsection{Significance of the Study}

This study would benefit the school administrators, grade 9 mathematics teachers and students, and the future researchers. The result of this study can be a basis for the school administrators in developing the school curriculum for academic improvement of the students. It would guide the grade 9 mathematics teachers to the learning approach they will apply to the learners for an effective learning process. If the study group is found to be effective, they can use this in their class and the grade 9 students would be benefited and they might have better achievement in Trigonometry. Finally, this study would also serve as a guide to future researchers to have a similar study and develop an action research that aims to contribute towards school improvement.

\subsection{Scope and Delimitation}

This study focused on the effects of study groups on grade 9 students' achievement in problem solving. Pretest and posttest were used to determine the effects of study groups on Grade 9 student's achievement in problem solving. It covered topics on Trigonometry specifically the six trigonometric ratios, special angles, and the angle of elevation and depression. It was limited to all students in the two classes consisting of 22 students from one class and 27 students from another class. Comparison of the scores of the students on the pretest before the study group and on the posttest after the study group was carried out in this study. It was conducted during the School Year 2015-2016 at a public High School in the province of Nueva Vizcaya, Philippines.

\subsection{Conceptual Framework}

Teachers are engaged in the active construction of knowledge about cooperative learning in the process of implementation of the constructivist approach. This means that there is a development of new concepts as reflected when cooperative learning is used in the classroom (Siegel, 2005). Cooperative learning is a method used in teaching that emphasizes group work and a strong sense of community. It focuses on the belief that students can learn better when they are working with their friends. It involves groups of students working on a given task. It is considered rich in educational strategy because it can elaborate student interactions (Siegel, 2005). Several studies reveal the positive effect of the study group or cooperative learning in the performance of the students in mathematics (Charry, 2005; Lau, 2006; Vaughan, 2002; Tarim \& Akdeniz, 2007; Dotson, 2001; Kalaian \& Kasim, 2014; Nebesniak, 2007). The same result was also revealed even when applied in Physics (Hussain, Anwar, \& Majoka, 2011; Adolphus, Alamina, \& Aderonmu, 2013) or economics (Yamarik, 2007). In addition, the difficulty encountered by the students in trigonometry despite its importance such as giving students good practice in employing the algebraic skills, its benefit in thinking processes (Vajiac \& Snow, 2009) is also considered. It is a part of the high school mathematics curriculum particularly in grade 9 in the Philippines because the subject also can serves as an important precursor to calculus as well as college level 
courses (Weber, Knott, \& Evitts, 2008). With the nature of teaching in Trigonometry that emphasizes procedural, paper-and-pencil skills at the expense of deep understanding (Hirsch, Weinhold, \& Nichols 1991, as cited by Weber, Knott, \& Evitts, 2008), its importance in grade 9 students and the evidences revealing the study group can improve achievement of students led the researcher to determine the effect of study groups on Grade 9 students' achievement in solving Trigonometric problems. Figure 1 shows the Input-Process-Output design used in the study.

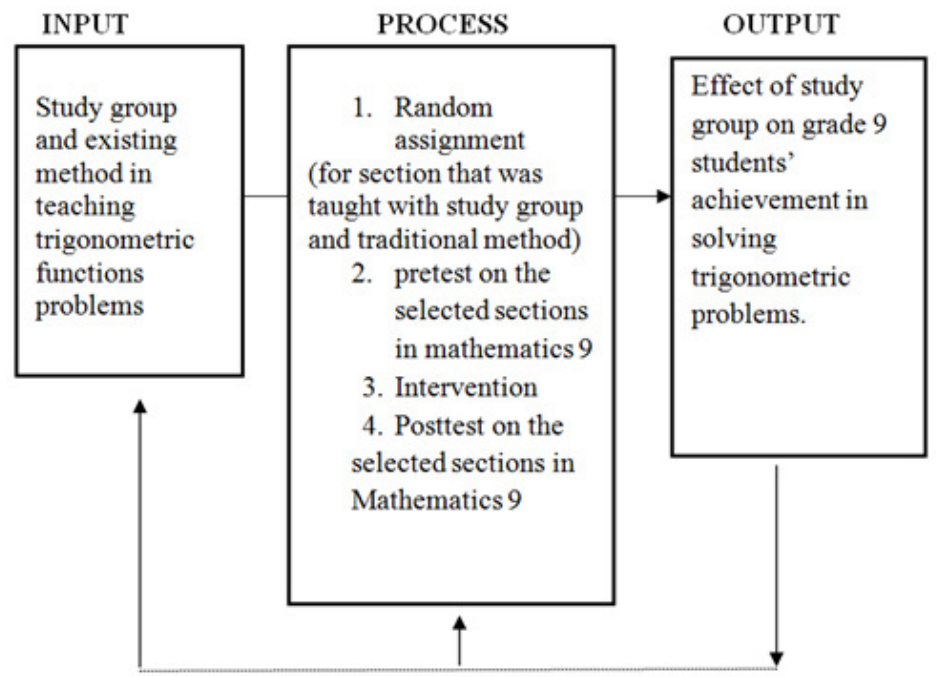

F E E D B A C K

Figure 1. Research Paradigm

The input included the interventions conducted in the selected sections in Mathematics 9. The process was the procedure in gathering the data which were randomly selected the section that was taught with the study group and the existing method. Before the interventions, the students were given pretest on the selected section in math 9. After the students were taught the topics on trigonometry with study group and existing method, posttest was given to the students in both groups. The output was the effects of study groups on grade 9 student's achievement in problem solving.

\section{Research Methodology}

\subsection{Research Design}

The research used true experimental design particularly pretest-posttest control group design. The study was also a quantitative type of research and descriptive-comparative because it considered the scores of the students to describe their achievements and compared it after the intervention with the study group and the existing method. The research design is shown below.

\begin{tabular}{|c|c|l|c|}
\hline Group & Pre-test & \multicolumn{1}{|c|}{ Teaching Method } & Post-test \\
\hline $\mathrm{R}$ & $\mathrm{P}_{1}$ & Existing Method & $\mathrm{P}_{2}$ \\
\hline $\mathrm{R}$ & $\mathrm{P}_{1}$ & Study Group Method & $\mathrm{P}_{2}$ \\
\hline
\end{tabular}

where:

$\mathrm{R}=$ Randomly assigned

$\mathrm{P}_{1}=$ pretest of the experimental and control group taught with the existing method

$\mathrm{P}_{2}=$ posttest of the experimental and control group taught with the existing method 


\subsection{Research Environment}

The research was conducted at Tuao High School, a public high school in the province of Nueva Vizcaya located in the Philippines particularly in the two sections in Grade 9. The selected High School caters students from grade 7 to grade 10. The average class size is around 25 students with a total population of 252 students. The school has a total of 14 rooms and it is currently building the additional rooms for the future Grade 11-12 students during the conduct of the study. Overall, the High School has at least one canteen, computer laboratory, general academic classroom, science laboratory, library, and office.

\subsection{Sampling and Subjects of the Study}

The subjects of the study were the Grade 9 students from two sections in a public high school. There were 22 students from one section and 27 students from the other section. Random assignment was used in determining class that received the intervention using study group method and existing method. The pretest score of the students in both groups was comparable, there was no significant difference. Both classes in the experimental and control group got a score that ranges from 6-10 indicating that the initial knowledge of two groups in the selected topic in trigonometry is the same.

\subsection{Research Instrument}

An adapted standardized pretest from the Learner's Module for Mathematics 9 by Department of Education (DepEd) in the Philippines was used. In the DepEd Order No. 73 S. 2012, the standard based-assessment was implemented to sustain the progressive roll-out starting with Grades 1 and 7 of the $\mathrm{K}$ to 12 Curriculum in public and even private elementary and secondary schools all over the country. According to Malipot (2015), DepEd has created a technical working group who was in charge of formulating and evaluating assessment tools measuring the effectiveness of the implementation of the K-12 curriculum through internal and external measures which mean that the assessments of the DepEd were undergone through tests. Modified instrument for posttest was used which is parallel to the pretest. The pretest and posttest were multiple choice test type and 20 -item tests. The instrument used aims to illustrate the six trigonometric ratios, determine the trigonometric ratios involving special angles, illustrate angles of elevation and angles of depression and use trigonometric ratios to solve real-life problems involving right triangles. Lesson plans and lesson guide using study groups and existing method checked by mathematics teachers were also included as guides to perform in the intervention. The lesson guide using study groups was the instructions in solving the problems that was given by group.

\subsection{Data Gathering Procedure}

The study involved three phases: pre-experimental activities, experiment proper and post-experimental activities. The first phase was the administration of the pretest on the selected section in Mathematics 9. Before the intervention with study group and the method, the students were given a pretest on trigonometric ratios, special angles, and angles of elevation and depression. The second phase was the employment of the teaching strategies for the participants, existing method to the control group and with study group to the experimental group. The control group was taught with the existing method within two weeks. All the activities of the students were by individual. While the experimental group was taught with study group method within two weeks. All the activities of the students were done by group. The third phase was the administration of the posttest on the trigonometric ratios, special angles, and angles of elevation and depression on mathematics 9 after the employment of the study group.

\subsection{Treatment of the Data}

Achievements of the students in solving trigonometric problems were described through their scores and gain scores. The gain scores called achievement in the study was the difference between the posttest score and 
pretest score. The achievement of the students was presented in frequency distribution table. Normality test was conducted to determine the appropriate test for the data. Non-parametric test was used in finding for the significant difference between achievements of the students before and after the study group method. The pretest and posttest scores were paired using Wilcoxon rank test. Parametric test was used to compare achievement of students before and after the existing method though t-test for paired samples; and between experimental and control group through non-parametric test, Mann-Whitney U test. Effect size was also computed using online calculator (Lenhard \& Lenhard, 2016).

\section{Results}

\subsection{Achievement of the Students in Problem Solving}

To describe the achievement of the students in problem solving, frequency count and percentage of the scores of the students in the two interventions and in overall were used to count how many students got the scores of 1-5, 6-10 and 11-15 on the pretest and posttest as shown in table 1 and was further illustrated in table 2 showing the decrease and increase on the scores after the two interventions.

\section{Table 1}

Frequency Count and Percentage of the Scores of the Students in Two Interventions and in Overall

\begin{tabular}{lcccccccccccc}
\hline & \multicolumn{4}{c}{ Experimental group } & \multicolumn{4}{c}{ Control group } & \multicolumn{3}{c}{ Overall } \\
Score & Pre & Post & Pre & Post & Pre & Post & Pre & Post & Pre & Post & Pre & Post \\
& $\mathrm{f}$ & $\%$ & $\mathrm{f}$ & $\%$ & $\mathrm{f}$ & $\%$ & $\mathrm{f}$ & $\%$ & $\mathrm{f}$ & $\%$ & $\mathrm{f}$ & $\%$ \\
\hline $1-5$ & 15 & 55.6 & 0 & 0 & 8 & 36.4 & 5 & 22.7 & 23 & 46.9 & 5 & 10.2 \\
$6-10$ & 12 & 44.4 & 3 & 11.1 & 14 & 63.6 & 16 & 72.7 & 26 & 53.1 & 19 & 38.8 \\
$11-15$ & 0 & 0 & 24 & 88.9 & 0 & 0 & 1 & 4.5 & 0 & 0 & 25 & 51.0 \\
$16-20$ & 0 & 0 & 0 & 0 & 0 & 0 & 0 & 0 & 0 & 0 & 0 & 0 \\
Total & 27 & 100.0 & 27 & 100 & 22 & 100 & 22 & 100 & 49 & 100 & 49 & 100 \\
\hline
\end{tabular}

As gleaned in Table 1, majority (88.9\%) of the students in experimental group got scores of 11-15 in the posttest while most $(44.4 \%)$ of the students got scores of 6-10 in pretest. This indicates that the scores of the students in the posttest were higher than the scores in posttest showing that students improve their score in solving problems on trigonometric ratios, special angles, and angles of elevation and depression. This further show that the scores increased after the intervention of integrating study group was conducted.

For the control group, majority of the students got a score of 6-10 on the posttest. Since there was an increase in frequency count and percentage from $14(63.6 \%)$ in the pre-test to $16(72.7 \%)$ in the scores in posttest of scores ranging from 6 to 10 and decrease from $8(36.4 \%)$ to $5(22.7 \%)$ in scores $1-5$, then this indicates that an improvement occur in the score of the students in the posttest in trigonometric problem solving specifically on trigonometric ratios, special angles, and angles of elevation and depression. This shows that the scores of the students from the pretest to the posttest improved. This means that existing method improved the students' scores. Overall before the interventions, majority $(53.1 \%)$ of the students got a score of 6-10 and after the interventions more than half of the students (51\%) got a score of 11-15.

Table 2 presents the achievement of students in the two groups. In class with study group, there was more increase by 3-11 points compared with only 1 student with decrease in score. This further reveals that the intervention of integrating study group can increased the student by 3 to 11 points. On the other hand, the decrease and increase of scores after the existing method was also shown in the table. This shows that some students decreased their scores by 1 to 6 points and some increased by 1 to 8 points. It also reveals that some neither increased nor decreased. Hence, the existing method can increase, decrease and neither decrease nor decrease the students score in problem solving in trigonometry. Over all, the result reveals that either with study group or existing method can either increase; decrease or neither increase nor decrease the scores of the students. 
Gurat, M., \& Sagun, M. J.

Table 2

Frequency of the Achievement in the Intervention with Study Group, Existing Method and in Overall

\begin{tabular}{|c|c|c|c|c|c|c|}
\hline \multirow{2}{*}{ Achievement } & \multicolumn{2}{|c|}{ With study group } & \multicolumn{2}{|c|}{ Existing Method } & \multicolumn{2}{|c|}{ Over all } \\
\hline & $\mathrm{F}$ & $\%$ & $\mathrm{f}$ & $\%$ & $\mathrm{f}$ & $\%$ \\
\hline-6.00 & 1 & 3.7 & 1 & 4.5 & 2 & 4.1 \\
\hline-3.00 & 0 & 0 & 1 & 4.5 & 1 & 2.0 \\
\hline-1.00 & 0 & 0 & 3 & 13.6 & 3 & 6.1 \\
\hline .00 & 0 & 0 & 4 & 18.2 & 4 & 8.2 \\
\hline 1.00 & 0 & 0 & 3 & 13.6 & 3 & 6.1 \\
\hline 2.00 & 0 & 0 & 2 & 9.1 & 2 & 4.1 \\
\hline 3.00 & 2 & 7.4 & 3 & 13.6 & 5 & 10.2 \\
\hline 4.00 & 4 & 14.8 & 2 & 9.1 & 6 & 12.2 \\
\hline 5.00 & 5 & 18.5 & 2 & 9.1 & 7 & 14.3 \\
\hline 6.00 & 4 & 14.8 & 0 & 0 & 4 & 8.2 \\
\hline 7.00 & 6 & 22.2 & 0 & 0 & 6 & 12.2 \\
\hline 8.00 & 3 & 11.1 & 1 & 4.5 & 4 & 8.2 \\
\hline 9.00 & 1 & 3.7 & 0 & 0 & 1 & 2.0 \\
\hline 11.00 & 1 & 3.7 & 0 & 0 & 1 & 2.0 \\
\hline Total & 27 & 100.0 & 22 & 100.0 & 49 & 100.0 \\
\hline
\end{tabular}

\subsection{Significant difference between the achievement of the students in problem solving before and after the} intervention with study group and the existing method

Table 3 and 4 shows the significant difference between the achievement of the students in problem solving before and after the intervention with study group and the existing method. Table 3 reveals the Wilcoxon rank test result to reveals the negative ranks, positive ranks and ties in the class with study group intervention. The result of Wilcoxon rank test on significant difference was also shown in the table.

Table 3

Difference between the achievement in problem solving before and after the Intervention with Study Group

\begin{tabular}{|c|c|c|c|c|c|}
\hline & & $\mathrm{n}$ & Mean Rank & Sum of Ranks & Test Statistic \\
\hline \multirow{4}{*}{ Posttest score-Pretest score } & Negative Ranks & $1^{\mathrm{a}}$ & 1.00 & 1.00 & \multirow{4}{*}{$\begin{array}{l}\mathrm{Z}=-4.53^{\mathrm{d}} \\
p<0.01^{* *}\end{array}$} \\
\hline & Positive Ranks & $26^{\mathrm{b}}$ & 14.50 & 377.00 & \\
\hline & Ties & $0^{\mathrm{c}}$ & & & \\
\hline & Total & 27 & & & \\
\hline
\end{tabular}

Table 3 reveals that 1 student from class with study group class got a negative rank which means that posttest score was lower than pretest score and 26 students got a positive rank which means that the posttest score was higher than the pretest score. The result also reveals that nobody got the same score in pretest and posttest. Furthermore, Wilcoxon rank test result reveals that there was significant difference between the achievement of the students in problem solving before and after the intervention with study group $(\mathrm{Z}=-4.53$, $p<0.01)$.

This means that the intervention with study group was effective in teaching trigonometric problems. Possible reasons of improvement are other effects of study group or cooperative/ collaborative learning. These include the effect that teachers and students were motivated and enjoyed by the differentiated instruction (Tieso, 2002), students became more motivated, not competitive and more aware of the process of problem solving (Morgan, 2005). It can also increase the confidence level of the students (Nebesniak, 2007). Moreover, Table 4 also reveals the significant difference between the achievement of the students in problem solving before and after the existing method. 
Effect of study group on grade 9 students' achievement in solving trigonometric problems

Table 4

Difference between the achievement in problem solving before and after the Existing Method

\begin{tabular}{llccccc}
\hline & Mean & N & Std. Deviation & Std. Error Mean & Test Statistic \\
\hline \multirow{2}{*}{ Pair 1 } & Pretest score & 5.68 & 22 & 1.94 & .41 & $\mathrm{t}(21)=-2.12$, \\
& Posttest score & 7.05 & 22 & 2.46 & .52 & $p=046^{*}$ \\
\hline Note. ${ }^{*}$ significant at 0.05 level & **significant at 0.01 level & & &
\end{tabular}

Table 4 shows that the mean of the pretest and posttest of the class that were taught with the existing method differs by 1.36 where the mean of the post score $(M=7.05, S=2.46)$ was higher than of the pretest score $(M=5.05$, $\mathrm{S}=2.46$ ). Furthermore, the t-test for paired samples result exposes that there was a significant difference between the achievement of the students in problem solving before and after the existing method, $\mathrm{t}(21)=-2.12, p=0.046$. This indicates that the even the existing method was also effective in teaching trigonometry.

\subsection{Significant difference between the achievements of the students when they are taught with study groups and with the existing method}

Table 5 shows the significant difference between the achievement of the students when they are taught with study groups and the existing method.

Table 5

Difference between the achievements when they are taught with study groups and existing method

\begin{tabular}{|c|c|c|c|c|c|c|}
\hline & Intervention & $\mathrm{N}$ & Mean Rank & Sum of Ranks & Test Statistic & $\begin{array}{c}\text { Effect size } \\
d_{p p c 2}\end{array}$ \\
\hline \multirow{3}{*}{ Achievement } & with study group & 27 & 33.44 & 903.00 & $\mathrm{U}=69, p<0.01 * *$ & 2.61 \\
\hline & Existing method & 22 & 14.64 & 322.00 & & \\
\hline & Total & 49 & & & & \\
\hline
\end{tabular}

Note. *significant at 0.05 level **significant at 0.01 level

$\mathrm{d}_{\mathrm{ppc} 2}$-effect size for mean differences of groups with unequal sample size within a pre-post-control design.

Table 5 reveals that the achievement of the students in intervention with the study group (Mn rank = 33.44) was higher the achievement the existing method (Mn rank =14.64). Furthermore, there was a significant difference between the achievement with the study group and existing method, $\mathrm{U}=69, p<0.01$. This indicates that the intervention with study group was more effective than the existing method in teaching trigonometry. Moreover, the result also revealed a large effect size (2.61), which is above 0.8 (Morris, 2008). This further means that the score of an average student in the class with study group is 2.61 higher than the average student in the class given existing method.

Similarly, a study conducted by Adolphus, Alamina, and Aderomu (2013), found that there was a significant difference between the abilities among students taught using collaborative learning strategy and those taught with the usual method. Also, this was similar to the result of the study made by Hussain, Anwar, and Majoka (2011). They found that performance with peer group activity-based method was better than existing lecture method. In the same way, this was supported by the study of Charry (2005) in which the small groups solve problems better than the individuals who worked alone. Studies of Lau (2006), Vaughan (2002), Tarim and Akdeniz(2007), Dotson (2001), Kalaian and Kasim (2014), and Nebesniak (2007) also yielded the same result.

With the result of the current study and the related studies, it suggests that the intervention with study group can also be used effectively in teaching trigonometry. The study group method can be used to improve the performance of the students particularly in mathematics subjects, where most of the students find it difficult. Aside from that, related studies also showed other effects of study group such as being motivated, more aware of process in problem solving and increase confidence level. Moreover, it can also make students enjoy the lessons in trigonometry. 


\section{Conclusions}

Based on the findings, the following conclusions are arrived at:

$>$ Majority of the students increased in their achievements in trigonometric problem solving.

$>$ There was a significant difference between the achievement of the students in problem solving before and after the intervention. The intervention with the study group and existing method can improve the students in solving trigonometric problems.

$>$ There was a significant difference between the achievements of the students when they are taught with study groups and the existing method. The intervention with study group was more effective than the existing method.

\subsection{Recommendations}

From the research findings, the following are recommended:

$>$ Teachers may integrate study groups in teaching problem solving in trigonometry and even in other mathematics subjects.

$>$ Schools encourage the use of Student Study Group Program in their classes so that the students will have better achievement.

$>$ Further research to improve study groups in teaching mathematics.

Acknowledgement: We would like to acknowledge University Research Center (URC) headed by Dr. Fe Yolanda Gatan-del Rosario and the Mathematics department for the approval of this thesis.

\section{References}

Adolphus, T., Alamina, J., \& Aderonmu, T. (2013). The effects of collaborative learning on problem solving abilities among senior secondary school physics students in simple harmonic motion. Journal of Education and Practice, 4(25). Retrieved from http://www.iiste.org/Journals/index.php/JEP/article/view/9049/9276

Baghdadi, A., \& Keskes, S. (2014). The impact of small group interaction on learners' grammatical accuracy achievement. International Journal of Research Studies in Language Learning, 3(2), 85-100.

Brame, C., \& Biel, R. (2015). Setting up and facilitating group work: using cooperative learning groups effectively. Retrieved from http://cft.vanderbilt.edu/guides-sub-pages/setting-up-and-facilitating-group-work-using-cooperative-lea rning-groups-effectively/

Bressoud, D. (2010). Historical reflections on teaching trigonometry. The Mathematics Teacher, 104(2), 106-112.

Charry, K. (2015). Effects of group size on problem solving: study suggests small groups solve problems better. Retrieved from http://psychology.about.com/od/psychologynews/qt/groupsize.htm

Choi-Koh, S. (2003). Effect of a graphing calculator on a 10th-grade student's study of trigonometry. The Journal of Educational Research, 96(6), 359-369. https://doi.org/10.1080/00220670309596619

Cronin, M., \& McCabe, A. (2018). The benefits of individual versus group work in a biology based laboratory setting. International Journal of Research Studies in Education, 7(1), 65-76.

Department of Education. (2012). DO 73, s. 2012 - Guidelines on the assessment and rating of learning outcomes under the $\mathrm{K}$ to 12 basic education curriculum. Retrieved from http://www.deped.gov.ph/orders/do-73-s-2012 
Effect of study group on grade 9 students' achievement in solving trigonometric problems

Ding, M., Li, X., Piccolo, D., \& Kulm, G. (2007). Teacher Interventions in cooperative-learning mathematics classes. The Journal of Educational Research, 100(3), 162-175. https://doi.org/10.3200/JOER.100.3.162-175

Dotson, M. (2001). Cooperative learning structures can increase student achievement. San Clemente, CA: Kagan Publishing. Retrieved from https://www.kaganonline.com/free_articles/research_and_rationale/311/Cooperative-Learning-Structure s-Can-Increase-Student-Achievement

Esmonde, I. (2009). Mathematics learning in groups: analyzing equity in two cooperative activity structures. The Journal of the Learning Sciences, 18(2), 247- 284. https://doi.org/10.1080/10508400902797958

Franz, D., \& Pope, M. (2005) Using children's stories in secondary mathematics. American Secondary Education, 33(2), 20-28.

Gallup, L. (2005). Math problematic for teens. Retrieved from http://www.gallup.com/poll/16360/Math-Problematic-US-Teens.aspx

Hadler, G. (2005). Solving problems using a group-advantage and disadvantage. Retrieved from http://www.itseducation.asia/groups.htm

Hussain, S., Anwar, S., \& Majoka M. (2011). Effect of peer group activity-based learning on students' academic achievement in physics at secondary level. International Journal of Academic Research, 3(1), 940-943.

Kalain, S., \& Kasim, R. (2014). A meta-analytic review of studies of the effectiveness of small group learning methods on statistics achievement. Journal of Statistics Education, 22(1), 1-20.

Kargas, C. ,\& Stephens, M. (2014). Using coaching to improve the teaching of problem solving to year 8 students in mathematics. In J. Anderson, M. Cavanagh, \& A. Prescott (Eds.), Curriculum in focus: Research guided practice (pp. 319-326). Sydney: MERGA.

Kotsopoulus, D. (2007). Mathematics discourse. It's like hearing foreign language. Retrieved from http://hybridalgebra.pbworks.com/f/mathematics+discourse+its+like+hearing+a+foriegn+language.pdf

Lau, C. (2006). What does peer group study have a students' learning commerce mathematics? A case study of diverse ethnic learning. Retrieved from http://ro.ecu.edu.au/cgi/viewcontent.cgi?article=1084\&context=ceducom

Lenhard, W., \& Lenhard, A. (2016). Calculation of effect sizes. Retrieved from https://www.psychometrica.de/effect size.html

Makewa, L., Gitonga, D., Ngussa, B., Njoroge, S., \& Kuboja, J. (2014). Frustration factor in group collaborative learning experiences. American Journal of Educational Research, 2(11), 16-22. https://doi.org/10.12691/education-2-11A-3

Malipot, H. (2015). DepEd sets assessment system for K-to-12 program. Manila Bulletin. Retrieved from http://www.mb.com.ph/deped-sets-assessment-system-for-k-to 12-program/

Morris, S. (2008). Estimating effect sizes from pretest-posttest-control group designs. Organizational Research Methods, 11(2), 364-386. http://doi.org/10.1177/1094428106291059

National Council of Teachers of Mathematics. (2016). Problem solving. Retrieved from http://www.nctm.org/Research-and-Advocacy/research-brief-and-clips/Problem-Solving/

Nebesniak, A. (2007). Using cooperative learning to promote a problem-solving classroom. Summative Projects for MA Degree. Retrieved from http://digitalcommons.unl.edu/mathmidsummative/3

Siegel, C. (2005). Implementing a research-based model of cooperative learning. The Journal of Educational Research, 98(6), 339-349. https://doi.org/10.3200/JOER.98.6.339-349

Siniguian, M. (2007). Students' difficulty in solving mathematical problems. Retrieved from http://www.academia.edu/9066326/Students_Difficulty_in_Solving_Mathematical_Problems

Tambychik, C., \& Meerah, M. (2010). Students' difficulties in mathematics problem-solving: what do they say? Procedia - Social and Behavioral Sciences, 8, 142-151. https://doi.org/10.1016/j.sbspro.2010.12.020

Tarim, K. (2009). The effects of cooperative learning on preschoolers' mathematics problem-solving ability. Educational Studies in Mathematics, 72(3), 325-340. https://doi.org/10.1007/s10649-009-9197-x

Tarim, K., \& Akdeniz, F. (2008). The effects of cooperative learning on Turkish elementary students' mathematics achievement and attitude towards mathematics using Tai and Stad Methods. Educational 
Studies in Mathematics, 67(1), 77-91. https://doi.org/10.1007/s10649-007-9088-y

Tieso, C. (2002). The effects of grouping and curricular practices on intermediate students' math achievement. University of Alabama Tuscaloosa, Alabama. Retrieved from http://www.gifted.uconn.edu/nrcgt/reports/rm02154/rm02154.pdf

Tilan, L. (2003). Effects of small-group activities on the mathematics achievement and attitude of the third year high school students (Unpublished thesis). Graduate Faculty of the School of Arts and Sciences, Saint Mary's University, Bayombong Nueva Vizcaya.

Vajiac, B., \& Snow, J. (2009). Mathematical roots: can a sixth grader do trig? Mathematics Teaching in the Middle School, 15(3), 176-180.

Vaughan, W. (2002). Effects of cooperative learning on achievement and attitude among students of color. The Journal of Educational Research, 95(6), 359-364. https://doi.org/10.1080/00220670209596610

Walmsley, A., \& Muniz, J. (2003). Cooperative learning and its effects in a high school geometry classroom. The Mathematics Teacher, 96(2), 112-116.

Weber, K., Knott, L., \& Evitts, T. (2008). Teaching trigonometric functions: lessons learned from research source. The Mathematics Teacher, 102(2), 144-150.

Wiersema, N. (2000). How does collaborative learning actually work in a classroom and how do students react to it? A brief reflection. Retrieved from http://www.city.londonmet.ac.uk/deliberations/collab.learning/wiersema.html

Williams, K. (2003). Writing about the problem-solving process to improve problem-solving performance. The Mathematics Teacher, 96(3), 185-187.

Yamarik, S. (2007). Does cooperative learning improve student learning outcomes? The Journal of Economic Education, 38(3), 259-277. https://doi.org/10.3200/JECE.38.3.259-277 